\title{
Freedoms and Restrictions of Translator's Subjectivity in Literary Translation
}

\author{
CAI Chen-qing \\ China Youth University of Political Studies, Beijing, China
}

\begin{abstract}
With the translation studies leaning to target-language, the translator's subjectivity has been paid more and more attention by translation scholars. It is noticed gradually that translation is actually a dynamic and complex process, during which the translator, acting as a reader of the source text and also a writer of the target text, will unavoidably add something subjective in his or her translation. Since literary translation is interwoven with more cultural and social elements, the translator has to make a choice between loyalty and violation, getting freedom and being restricted when he or she confronts with all the clashes and conflicts between the source language culture and the target language culture.
\end{abstract}

Keywords: translator, subjectivity, literary translation

\section{Introduction}

In the long history of translation studies, the emphasis has always been put on the transitional process between the source language and target language and the comparison between the original text and the translated version. The general expectation is that the translation should give a complete transcript of the ideas of the original work while the style and the manner of writing should be of the same character with that of the original (Tytler, 2007). In this case, the translator is not encouraged to involve in the reproduction. He is told to be as free as possible from personal intrusions; he is warned not to "distort the message to fit his own intellectual and emotional outlook"; he is required to minimize "ego-involvement" (Nida, 1993, p. 154).

Consequently, personal elements of the translator are overlooked, and the translator's creativity is correspondingly prohibited. Along with it, numerous criteria such as "equivalence" and "faithfulness" are put forward by the translation theorists. And all these theories suggest that the translators should behave like a transparent glass which can reflect everything in the original text to the translated text. The translator is expected to be "invisible" as much as possible so that the original text and the original writer could be more "visible" to the readers (Venuti, 1995). However, all the activities have their own subjects and translation is no exception. Translators are the subjects of translation, and their subjectivity deserves scholars' notice. It must be realized that the whole process of translation cannot be free from the translator's influence completely.

Throughout the Western translation history, many translation theorists and researchers have ever put forward their own understanding about translation and the significance of translator's subjectivity. In the late Roman Empire Ages, one outstanding translation theorist St. Jerome believed that the translator can make the

CAI Chen-qing, master, Project Coordinator With the International Exchange Division, China Youth University of Political Studies. 
translated work as beautiful as the original by injecting his own styles and attitudes (TAN, 2004). In the 20th century, the translation theory advanced rapidly. French sociologist Robert Escarpit raised the term "creative treason" and regarded translation as a process of creative treason (XIE, 2003). This is especially true in the translation of literary works. Since literary woks always pursue aesthetic beauty, the translator must use his own aesthetic taste and creativity to satisfy this need.

In China, the studies on translators have claimed a long history, but a systemic study of the translator-oriented approach did not start until the 1980s. In recent years, increasing attention has been paid to the translator's subjectivity, which can also be seen in the dissertations of ZHA Ming-jian, TIAN Yu, and XU Jun. In ZHA and TIAN's (2003) opinion, the translator is the subject of translation and an important participant in the construction of a national culture. XU (2003) recommends paying much more attention to translators, not only to their important roles but also to their ideas and opinions. What is more, he regards the translator's awareness of his or her subjectivity as the translator's own personality, aesthetic pursuit, and creativity.

Compared with traditional translation studies, these researchers examine the translator from a new perspective and obtain more scientific understanding of the role the translator plays in translation activity. It is an undeniable truth that the translation works will be inevitably influenced by the translator's subjectivity. In the process of translation, especially in literary translation, the translator cannot help injecting these factors in the translation and reproduce a product that combines both the author's idea and his own opinion.

Based on these researchers' previous studies, this paper focuses on the restrictions and freedoms of the translator's subjectivity through a comparative study on different versions of literary translation and conclusions are naturally drawn that the translator's subjectivity can neither be ignored nor exaggerated.

\section{Freedoms and Restrictions of Subjectivity in Literary Translation}

Scholars' preoccupations of the restrictions and freedom, loyalty and treachery in translation have stretched throughout centuries. So, to what extent are translators given freedom in their performance and how many restrictions should translators bear in mind when they can release their imagination during the literary translation? In this paper, these issues will be approached respectively.

\section{Freedoms}

Brilliant translators are often surprised at the manner in which creative solutions seem to pop into their heads. And in many respects, creative translating is like portrait painting and artistic musical performance (MAO \& LIAO, 2005). Therefore, the involvement of the translator's subjectivity or some freedom for the translator's creative ability will only perfect the translated work but not make it worse.

On the contrary, if the translator pays too much attention to the original text without leaving himself any freedom, the readers sometimes may find the difficulty in understanding. The following is a comparison of translations between one doing "faithful translation" and the other properly making the translator's subjectivity work by enjoying the freedom of translation.

Example (1) I am never at a loss for a word; Pitt is never at a loss for the word.

a. 我总能找到一个词，而皮特总能找到一个恰当的词。

b. 我总是滔滔不绝，而皮特则是字字珠现。(MAO \& LIAO, 2005, pp. 26-27)

Example (2) If we do not hang together, we shall most assuredly hang separately.

a. 如果我们不能紧密的团结在一起, 那就必然分散地走上绞刑台。 
b. 我们必须共同上战场，否则就得分别上刑场。(MAO \& LIAO, 2005, p. 27)

From Examples (1)-(2), it is clearly noticed that (1a) and (2a) are the "faithful" translation of the original sentence. However, they are not acceptable to the Chinese readers or too wordy. (1b) and (2b) are much more proper and concise, although they, to some extent, betray the exact structure or the figures of speech in the original sentence. And in (1b) and (2b), it is not difficult to notice that there is a contribution of the translators' subjective creativity and it is quite necessary for the translators to be given some freedom during literary translation.

What is more, some freedom could help the translator produce some excellent works. And what follows is an example which could clearly show this point.

Example (3) "Did you say 'pig' or 'fig'?" said the Cat.

"I said 'pig'," replied Alice... (Carroll, 1965/1988, p. 89)

那猫问道，“你刚才说”猪” 还是“书” ?”

阿丽思答道，“我说的是“ 猪’” …... (Carroll, 1965/1988, p. 67)

In Example (3), if translator pays too much attention to faithfulness and translates “fig” as “无花果”, it will definitely confuse the reader since “猪” and “无花果” cannot be mistaken acoustically. But a little creative change from “无花果” to “书” obviously helps to get the same effect from the target-language readers as that from the source-language readers and this change really should ascribe to the translator's subjectivity.

Therefore, handling with the original text, the translator should not make himself a slave and bind his own feet and hands. Actually, the best translated works need the release of translator's subjectivity which means it is the translator's creativity that makes the translated works excellent. As long as the translators are given some freedom in the process of translation, the translated works will surely become better and better.

\section{Restrictions}

Although the translator's subjectivity is of great significance, it is not to say the translator has the absolute power to interpret the original text in his own will. Otherwise, the translation practice would be out of order. The Italian scholar, Umberto Eco (1962/2005), states that the open reading must be based on the text which leads to the result that the process of translation must be restricted to the text. In other words, the translator's subjectivity should not be exaggerated. And the original text still should be the start point of the translation. Example (4) would be very helpful to understand this point.

Example (4) The original text: He is lying on his back, fixing his eyes on the shining stars in the sky. Version 1: 他坦腹高卧, 遥望星空, 神游天际。

Version 2: 他仰卧着, 直目天空中闪伢的星星。(FU \& LV, 2004, p. 39)

Version 1 is vivid and reads fluently but many words the translator used are not the exact meaning the original text delivered. Therefore, if this sentence is put into the context, then contradictions and inappropriate points may appear.

So, even though the existence of a thousand Hamlets is reasonable if there were a thousand translators, it is not acceptable if the Hamlet's appearance changed so much that this famous image could not be recognized. And if that condition really happens, the translation practice will become no longer meaningful as well.

It is always said that the translator is like a dancer with fetters. And those "fetters" are just the restrictions of the translator's subjectivity. 


\section{Approaches to Control the Measures of Subjectivity}

"Faithfulness, expressiveness, and elegance" is always considered as a standard for translation. However, with the study in translator's subjectivity going further, its measure is also changing. Recently, there are more and more principles or criteria popped up, such as "the creative treason" (XU, 2003, p. 12), "the best resemblance" (GU, 2003, p. 343). And the author here would like to specially introduce one standard which is called the most sophisticated level that a translator could ever reach at. It is "going with your heart without breaking the restrictions" (CONG, 2007, pp. 55-56).

This new measure tells the translators that "not breaking the restrictions" or "being faithful to the original text" are only the most basic requirements or the lowest level of translation. It is never the final goal. And then on the precondition of "faithfulness", the translator should be given some freedom or some space to do the recreation work.

In this process, the translator must bring his multiple identities - as reader, interpreter, and writer into full play which means the translator should exchange view with the author and the source text, make full use of his aesthetic ability and imagination to concretize the indeterminacies and blankness in the source text. When coming to the stage of presentation, the translator has to reproduce not only the meaning but also the aesthetic information and the flavor of the original.

Second, the translator's subjectivity manifests in the translator's consciousness of the target language culture and readers. Since every translation activity proceeds from a certain cultural purpose. According to his awareness of the needs in the target language culture, the translator may take translation to strengthen certain ideology or literary view, or subvert the existing cultural or literary form for reform purpose.

Through the exploration of the translator's subjectivity, suggestions are put forward. The translators should firstly put the original text into a melting-pot, and secondly pour in the emotional reaction which the translators get as a reader. Then, in order to reproduce a new literary work, the translators should unite their consciousness of creativity and self-restraint at the same time and spare no effort to convey the message and flavors that the original text delivered to the maximum (FANG, 2004).

In conclusion, the translator's subjectivity is inevitable in the process of translation and it should not be ignored or prohibited. The freedoms and restrictions of translator's subjectivity are all necessary. And what should be carefully controlled is only its measures.

\section{Conclusion}

Translation is not only a language transfer, but also a recreational activity. It is especially true if it takes the translator's subjectivity into consideration. For a long time, the translator's subjectivity has not been recognized or permitted. The translator is only allowed to be existed as a "machine", which makes the direct communications between the author and readers possible. However, the translator's subjectivity began to be recognized and received increasing attention in recent years. The translation study field started to learn translation from the perspective of translators. With a new image which is creative, visible, and decisive, translators are regarded as subjective agents who produce the after-life of the source text and that is really impressive.

The translator's subjectivity consists of subjective initiative and constraints, freedoms and restrictions. Subjectivity represents the power of the subject in changing objective activities, which is manifested in every 
stage of the translation process, especially in literary translation.

After the recognition of this, the translator is supposed to perform his subjectivity in a possible space, making his individuality salient under the condition of a maximal conveyance of the original content and style. Meanwhile, due to the restrictions of translator's subjectivity, exaggerations of translator's subjectivity should be avoided and prohibited as well.

\section{References}

Carroll, L. (1865/1988). Alice's adventures in wonderland (Y. R. ZHAO, Trans.). Beijing: The Commercial Press.

CONG, Z. H. (2007). Research on translation theories of the Chinese classical poetry. Beijing: National Defend Industry Press.

Eco, U. (1962/2005). The open book (R. LIU, Trans.). Beijing: News Star Press.

FANG, M. Z. (2004). Translation studies and practice. Qingdao: Qingdao Press.

FU, J. M., \& LV, H. Y. (2004). Contemporary advanced English-Chinese translation. Shanghai: Shanghai University Press.

GU, Z. K. (2003). China and west: Comparative poetics and translatology. Beijing: Tsinghua University Press.

MAO, R. G., \& LIAO, S. (2005). Translators' practice. Beijing: China Translation \& Publishing Corporation.

Nida, E. (1993). Language, culture and translation. Shanghai: Shanghai Foreign Languages Education Press.

TAN, Z. X. (2004). A short history of translation in the West. Beijing: The Commercial Press.

Tytler, A. F. (2007). Essay on the principles of translation. Beijing: Foreign Language Teaching and Research Press.

Venuti, L. (1995). The translator's invisibility: A history of translation. London: Routledge.

XIE, T. Z. (2003). New horizon in translation research. Qingdao: Qingdao Publishing House.

XU, J. (2003). Creative treason and the establishment of the translational subjectivity. Chinese Translators Journal, 1, 12-14.

ZHA, M. J., \& TIAN, Y. (2003). On the subjectivity of the translator. Chinese Translators Journal, 1, 22-24. 